\title{
Adjuvant requirement for successful immunization with recombinant derivatives of Plasmodium vivax merozoite surface protein-1 delivered via the intranasal route
}

\author{
Daniel Y Bargieri/*, Daniela S Rosa/*, Melissa Ang Simões Lasaro/**, \\ Luis Carlos S Ferreira/**, Irene S Soares/***, Mauricio M Rodrigues $/ * /+$
}

\begin{abstract}
Centro Interdisiciplinar de Terapia Gênica *Departamento de Microbiologia, Imunologia e Parasitologia, Escola Paulista de Medicina, Universidade Federal de São Paulo, Rua Mirassol 207, 04044-010 São Paulo, SP, Brasil **Departamento de Microbiologia,

Instituto de Ciências Biomédicas ****Departamento de Análises Clínicas e Toxicológicas, Faculdade de Ciências Farmacêuticas, Universidade de São Paulo, São Paulo, SP, Brasil
\end{abstract}

Recently, we generated two bacterial recombinant proteins expressing 89 amino acids of the C-terminal domain of the Plasmodium vivax merozoite surface protein-1 and the hexa-histidine tag $\left(\mathrm{His}_{6} \mathrm{MSP}_{19}\right)$. One of these recombinant proteins contained also the amino acid sequence of the universal pan allelic T-cell epitope ( His $\left._{6} M S P 1_{19}-P A D R E\right)$. In the present study, we evaluated the immunogenic properties of these antigens when administered via the intra-nasal route in the presence of distinct adjuvant formulations. We found that C57BL/ 6 mice immunized with either recombinant proteins in the presence of the adjuvants cholera toxin (CT) or the Escherichia coli heat labile toxin $(L T)$ developed high and long lasting titers of specific serum antibodies. The induced immune responses reached maximum levels after three immunizing doses with a prevailing IgG1 subclass response. In contrast, mice immunized by intranasal route with His ${ }_{6} M S P 1_{19}$-PADRE in the presence of the synthetic oligonucleotides adjuvant CPG ODN 1826 developed lower antibody titers but when combined to CT, $C p G$ addition resulted in enhanced IgG responses characterized by lower IgG1 levels. Considering the limitations of antigens formulations that can be used in humans, mucosal adjuvants can be a reliable alternative for the development of new strategies of immunization using recombinant proteins of $\mathrm{P}$. vivax.

Key words: Plasmodium vivax - mucosal immunization - recombinant vaccines - adjuvants

Plasmodium vivax causes more than 40 million cases of malaria every year and an effective vaccine is greatly needed (reviewed by Mendis et al. 2001). Because in vitro large-scale cultures of $P$. vivax will probably not be available soon, a vaccine will have to be developed using recombinant DNA technology. The use of recombinant proteins to generate effective vaccines faces several challenges such as the limited number of adjuvants that can be used in humans. Based on that need, this field is evolving rapidly and a number of clinically acceptable adjuvant formulations have been described (reviewed by Singh \& O'Hagan 1999, 2002). Many of these adjuvants perform better than alum, the most used adjuvant licensed for human use. These new adjuvants are in most cases used by the parenteral route of immunization. However, some of them can also be used effi-

Financial support: Fapesp, The Millennium Institute for Vaccine Development and Technology, CNPq grant 420067/2005-1

${ }^{+}$Corresponding author: mrodrigues@ecb.epm.br

DYB, DSR, MASL Fapesp research fellowship; LCSF, ISS, MMR CNPq research fellowship

Received 5 February 2007

Accepted 10 April 2007 ciently by the mucosal route including synthetic oligonucleotides containing unmethylated $\mathrm{CpG}$ motifs (CpG ODN) and bacterial toxins such as cholera toxin (CT) and the heat-labile toxin (LT) produced by some enterotoxigenic Escherichia coli (ETEC) strains (reviewed by Holmgren et al. 2003). As an alternative administration route, mucosal-delivered vaccines offer several advantages over those injected by parenteral routes including the lack of iatrogenic infection risks, simple and painless administration, and induction of both systemic and secreted immune responses (Holmgren et al. 2005, Holmgren \& Czerkinsky 2006).

Recently, we generated two recombinant proteins containing 89 amino acids of the C-terminal region of the $P$. vivax merozoite surface protein- $1\left(\mathrm{MSP}_{19}\right)$ and the hexahistidine tag $\left(\mathrm{His}_{6}\right)$. The first recombinant protein was named $\mathrm{His}_{6} \mathrm{MSP}_{19}$. The second protein contained the amino acid sequence of the universal pan allelic T-cell epitope (PADRE) in addition to the His ${ }_{6} \mathrm{MSP}_{19}$ and was denominated His ${ }_{6} \mathrm{MSP}_{19}$-PADRE (Cunha et al. 2001). Both recombinant proteins were recognized by $\mathrm{IgG}$ antibodies from individuals recently exposed to $P$. vivax malaria suggesting that the presence of PADRE did not modify the epitopes of $\mathrm{MSP}_{19}$ recognized by human IgG (Cunha et al. 2001, Rodrigues et al. 2003).

The immunogenic properties of these recombinant proteins were studied by the parenteral immunization of C57BL/6 mice with formulations containing different adjuvants (Rosa et al. 2004). Mice developed high anti- 
body titers when immunized with either recombinant proteins emulsified in complete/incomplete Freund's adjuvant (CFA/IFA). Other adjuvants such as MPL/TDM and CpG ODN 1826 required the presence of the PADRE for maximal and long lasting antibody responses (Rosa et al. 2004). These results clearly indicated that immune responses induced by the universal T-cell epitope PADRE improved adjuvant-assisted immune response in the presence of specific adjuvant.

Based on these results, it was our intention to extend our studies on the immunogenicity of these recombinant proteins to establish whether mucosal adjuvants could be used to generate immune responses in mice. To address this question, we compared the serum antibody responses elicited by C57BL/6 mice immunized with vaccine formulations prepared with the $\mathrm{His}_{6} \mathrm{MSP}_{19}$-PADRE or $\mathrm{His}_{6} \mathrm{MSP}_{19}$ antigens and delivered via the intranasal route in the presence of the mucosal adjuvants CpG ODN 1826, CT and/or LT.

\section{MATERIALS AND METHODS}

Recombinant proteins containing P. vivax $M S P 1_{19}$ - The recombinant proteins were obtained exactly as described previously (Cunha et al. 2001). Purified proteins were analyzed by SDS-PAGE and stained with Coomassie blue or silver nitrate. A single band of $19 \mathrm{kDa}$ was observed. Protein concentration was determined by absorbance according to the following formula:

Concentration $(\mathrm{mg} / \mathrm{ml})=$ absorbance $280 \mathrm{~nm} \times \varepsilon 280 \mathrm{~nm} /$ molecular weight

$\varepsilon 280 \mathrm{~nm}=($ number of tryptophan $\times 5690)+$ (number of tyrosine $\times 1280$ )

Immunization of mice with the recombinant proteins $\mathrm{His}_{6} \mathrm{MSP}_{1}$ 19 $^{-}$PADRE or His ${ }_{6} M S P 1_{19}$. - Six to eightweek-old female C57BL/6 $\left(\mathrm{H}-2^{\mathrm{b}}\right)$ mice were purchased from Federal University of São Paulo, Brazil. Experiments were performed with approved consent of the Committee of Ethics of Universidade Federal de São Paulo-Escola Paulista de Medicina. Groups of six mice were immunized three times, two weeks apart, with 10 $\mu \mathrm{g}$ of recombinant protein in the presence of $2.5 \mu \mathrm{g}$ of CT (Sigma-Aldrich), or $2.5 \mu \mathrm{g}$ of LT and/or $10 \mu \mathrm{g}$ of CpG ODN 1826 (TCCATGACGTTCCTGACGTT) synthesized with a nuclease-resistant phosphorothioate backbone (Coley Pharmaceutical Group) as adjuvants. LT was purified by affinity chromatography as previously described (Lasaro et al. 2006) from the 25A-1 ETEC strain (O78:H12 LT-I/ST CFA/I ${ }^{+}$) isolated from a diarrheic child in São Paulo city and kindly supplied by Dr BEC Guth at the Federal University of São Paulo. Mice were immunized subcutaneously (s.c.) in the two hind footpads with the recombinant antigen mixed with adjuvant in a final volume of $50 \mu \mathrm{l}$ in each footpad, or intranasally (i.n.), drop by drop, assisted by a micropipette for a final volume of $8 \mu \mathrm{l}$ in each nostril. For the s.c. immunizations, the second and third doses were administered at the base of the tail in a $100 \mu \mathrm{l}$ volume.

Immunological assays - Antibodies to MSP $1_{19}$ in the mice sera were detected by ELISA essentially as de- scribed by Cunha et al. (2001). The antigen added to the plates was the recombinant protein $\mathrm{His}_{6}-\mathrm{MSP} 1_{19}(200$ ng/well) and the secondary antibody, conjugated to peroxidase, was goat anti-mouse IgG (KPL) diluted 1:4000. Each serum was analyzed in serial dilutions from 1:100 up to $1: 1,638,400$. The individual titers were considered as the highest dilution of serum that presented an $\mathrm{OD}_{492}$ higher than 0.1 . The results are presented as the $\log 10$ antibody titer of each immunized mouse.

Detection of IgG subclass responses was performed as described above, except that the secondary antibodies were specific for mouse $\mathrm{IgG1}, \mathrm{IgG} 2 \mathrm{~b}$, and IgG2c (all obtained from Southern Technologies) diluted 1:2,000. The results are presented as the mean of log antibody titers \pm SD of three animals per group.

The affinities of anti-His ${ }_{6} \mathrm{MSP}_{19}$ antibodies were assessed by a thiocyanate elution-based ELISA (Rosa et al. 2004). The procedure was similar to that described for the standard ELISA with the inclusion of an extra step. After the plates were washed following incubation of the pooled serum dilutions $(1: 20,000)$, ammonium thiocyanate, diluted in PBS, was added to the wells in duplicate or triplicate, in concentrations ranging from 0 to $8 \mathrm{M}$. The plates were allowed to stand for $15 \mathrm{~min}$ at room temperature before they were washed and the assay proceeded. The concentration of ammonium thiocyanate required to dissociate $50 \%$ of the bound antibody was determined. The percentage of binding was calculated as follows: $\mathrm{OD}_{492}$ in the presence of ammonium thiocyanate $\mathrm{X} 100 / \mathrm{OD}_{492}$ in the absence of ammonium thiocyanate.

Statistical analysis - The One-Way ANOVA, Students' $t$ test and the Tukey HSD test were used to compare the possible differences between the mean values of the different groups.

\section{RESULTS}

In the presence of the adjuvants $\mathrm{CT}, \mathrm{LT}$ or $\mathrm{CpG}$ ODN 1826, C57BL/6 female i.n. immunized with $\mathrm{His}_{6} \mathrm{MSP}_{19^{-}}$ PADRE or $\mathrm{His}_{6} \mathrm{MSP}_{1}$ induced high serum IgG titers. In all cases, maximal antibody responses were detected after the third immunizing dose (Fig. 1A). In contrast, i.n. administration of three doses of $\mathrm{His}_{6} \mathrm{MSP} 1_{19}$-PADRE or $\mathrm{His}_{6} \mathrm{MSP}_{19}$ in the absence of adjuvant failed to induce detectable specific antibody responses (Fig. 1A).

Statistical comparison of the different mouse groups revealed that the antibody titers of mice immunized with $\mathrm{His}_{6} \mathrm{MSP}_{1}{ }_{19}$-PADRE or $\mathrm{His}_{6} \mathrm{MSP} 1_{19}$ in the presence of CT or LT were similar after the third dose $(P>0.05)$. In both groups, we found significantly higher specific antibody titers to $\mathrm{His}_{6} \mathrm{MSP}_{19}$ when compared to animals immunized with $\mathrm{His}_{6} \mathrm{MSP}_{1}$-PADRE admixed with $\mathrm{CpG}$ ODN $1826(P<0.01)$. In addition, mice immunized via the s.c. route with $\mathrm{His}_{6} \mathrm{MSP}_{19}$-PADRE in the presence of CpG ODN 1826 developed higher serum antibody titers than those immunized with the same vaccine formulation by the i.n. route $(P<0.05)$ (Fig. 1A).

Two other vaccine regimens were also tested using the antigen $\mathrm{His}_{6} \mathrm{MSP}_{19}$-PADRE. First, we administered $\mathrm{CT}$ and CpG ODN 1826 together with the antigen by the i.n. route. This immunization induced similar levels of 
specific antibodies obtained when we used only CT as adjuvant $(P>0.05)$. In a different immunization regimen, mice were first s.c. primed with the antigen admixed with CpG ODN 1826 followed by two i.n. doses of the antigen admixed with CT. The final specific serum $\mathrm{IgG}$ levels in this group were similar to mice i.n. immunized with CT or LT and mice immunized s.c. with CpG ODN $1826(P>0.05)$ (Fig. 1A).

Determination of the specific $\operatorname{IgG}$ subclass responses revealed that mice immunized i.n. with $\mathrm{His}_{6} \mathrm{MSP}_{19^{-}}$ PADRE or $\mathrm{His}_{6} \mathrm{MSP}_{19}$ in the presence of CT or LT, elicited a prevailing $\mathrm{IgG} 1$ response. The ratio of $\mathrm{IgG} 1 / \mathrm{IgG} 2 \mathrm{c}$ varied from 158.5 to 501.2 , with LT in both cases (Fig.1B). The presence of $\mathrm{CpG}$ ODN in the vaccine for-

A

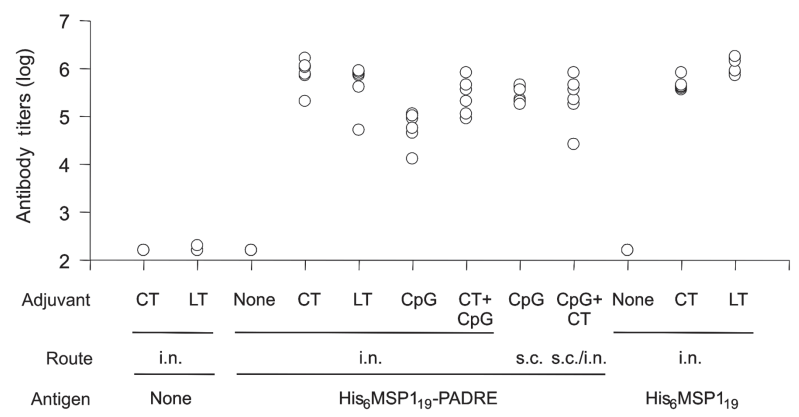

B

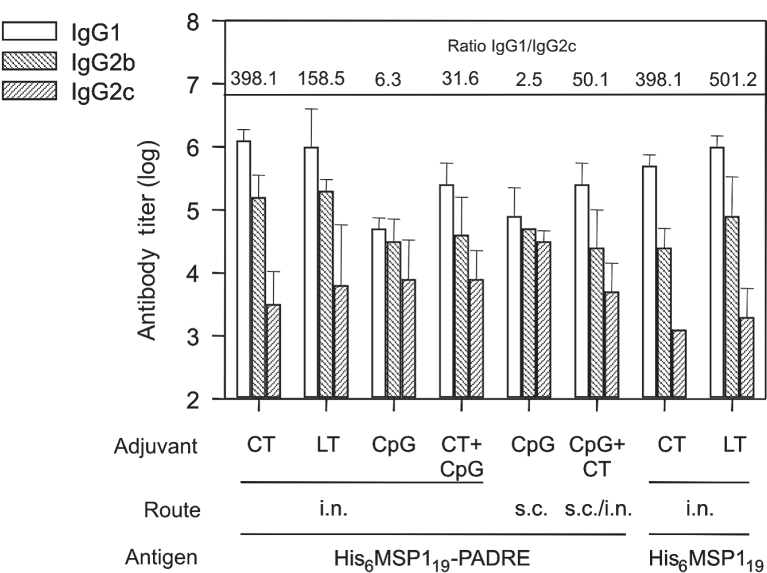

Fig. 1: magnitude and $\operatorname{IgG}$ subclasses of the antibody immune response of mice immunized with the recombinant proteins $\mathrm{His}_{6} \mathrm{MSP} 1_{19}$-PADRE or $\mathrm{His}_{6} \mathrm{MSP}_{19}$ in the presence of different adjuvant formulations. A: C57BL/6 mice were immunized i.n or s.c. with three doses of $10 \mathrm{mg}$ of recombinant protein, two weeks apart, in the presence or absence of the indicated adjuvants. Results are expressed as the logarithmic $\left(\log _{10}\right)$ antibody titer of each individual mouse after the third immunizing dose $(n=6)$. For statistical analyses see results section; B: specific antibodies of distinct IgG subclasses were detected with serum samples harvested 2 weeks after the third immunizing dose. Results are expressed as the mean of six mice \pm S.D. The $\mathrm{IgG} 1 / \mathrm{IgG} 2 \mathrm{c}$ ratios were indicated on the top of the figure. mulations significantly reduced this ratio, which varied from 2.5 (s.c. route) to $50.1(\mathrm{CpG}+\mathrm{CT}$, s.c./i.n immunization regimen) (Fig. 1B). These results clearly demonstrate the Th2 bias of the immune responses induced by the intra-nasal immunization in the presence of CT and LT. In contrast, CpG ODN 1826 modulates the immune response toward a more balanced Th1-Th2 pattern.

The longevity of the antibody immune response was also compared among groups of immunized C57BL/6 mice. We found that the serum $\mathrm{IgG}$ responses to $\mathrm{His}_{6} \mathrm{MSP}_{19}$ were extremely long lived in mice immunized with $\mathrm{His}_{6} \mathrm{MSP}_{1}{ }_{19}$-PADRE or $\mathrm{His}_{6} \mathrm{MSP}_{19}$ antigens in the presence of all tested adjuvants. No significantly faster decay of specific antibody responses was associated to a particular adjuvant (Fig. 2).

Antibodies induced after immunization with $\mathrm{His}_{6}$ MSP $1_{19}$-PADRE or $\mathrm{His}_{6} \mathrm{MSP}_{19}$ admixed with different adjuvants show similar affinities to the target antigen as indicated in Fig. 3.

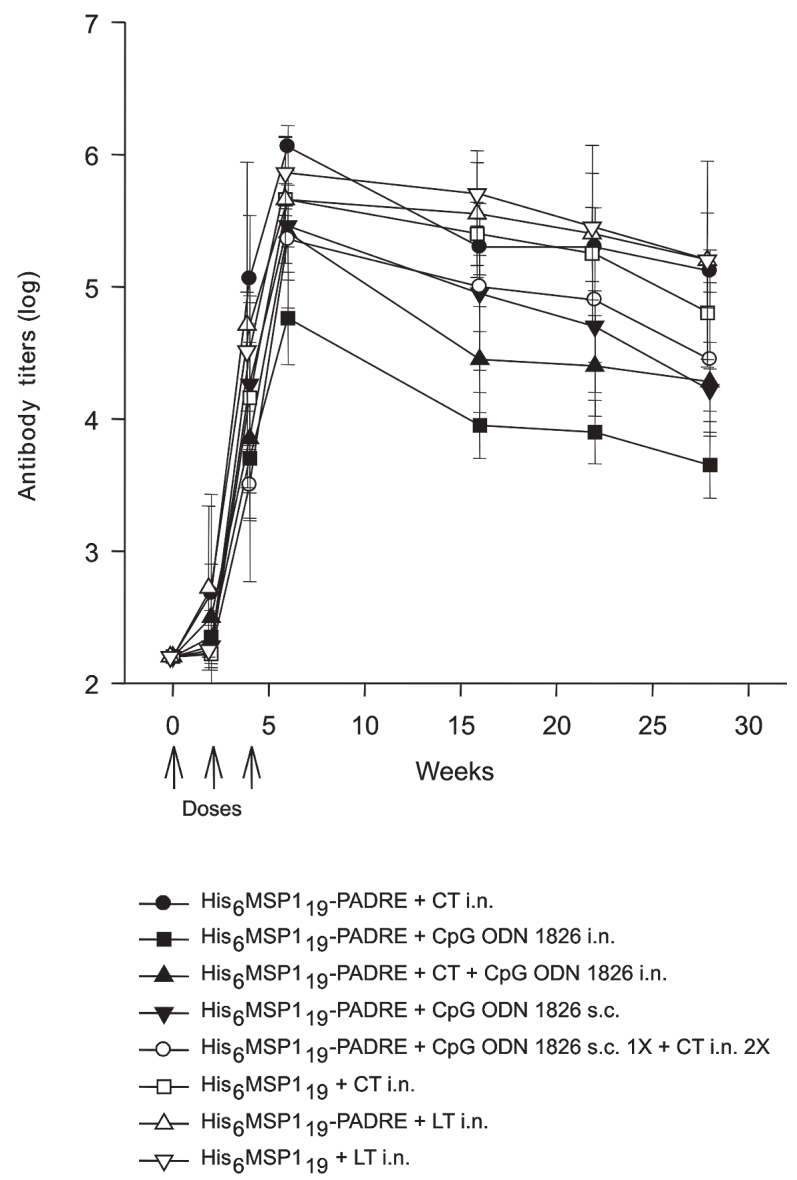

Fig. 2: longevity of the antibody immune responses elicited in C57BL/6 mice immunized with $\mathrm{His}_{6} \mathrm{MSP}_{19}$-PADRE or $\mathrm{His}_{6} \mathrm{MSP}_{19}$ in different adjuvant formulations. C57BL/6 mice were immunized i.n. or s.c. with three doses of $10 \mathrm{mg}$ of the recombinant proteins, two weeks apart, in the presence of the indicated adjuvants. Results are expressed as the mean of six mice \pm S.D. of log antibody titers detected at the indicated weeks after the first immunizing dose. 


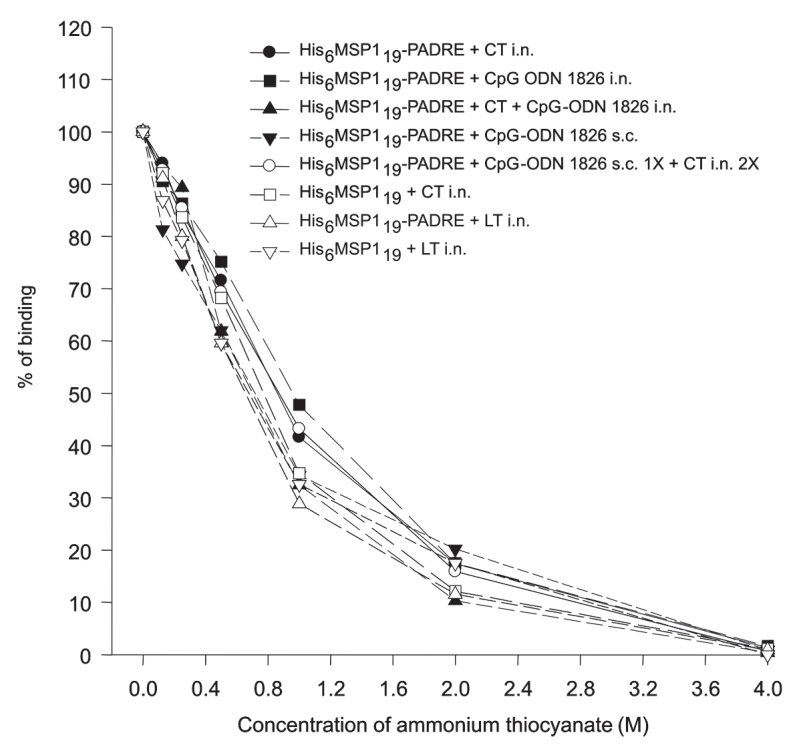

Fig. 3: affinity determination of specific anti-His ${ }_{6} \mathrm{MSP}_{19}{ }_{19} \mathrm{IgG}$ antibodies based on the thiocyanate elution method. Pooled sera from 6 C57BL/6 mice i.n. or s.c. immunized with three doses of $10 \mathrm{mg}$ of $\mathrm{His}_{6} \mathrm{MSP}_{19^{-}}$ PADRE or $\mathrm{His}_{6} \mathrm{MSP}_{19}$ together with the indicated adjuvant were tested in the presence of different concentrations of ammonium thiocyanate. Results are expressed as average of duplicate samples.

\section{DISCUSSION}

Our study demonstrated unequivocally that the recombinant proteins $\mathrm{His}_{6} \mathrm{MSP}_{19}$ and His ${ }_{6} \mathrm{MSP}_{19}$-PADRE of $P$. vivax are highly immunogenic to C57BL/6 mice when administered through the i.n. route in the presence of the mucosal adjuvants CT or LT. These formulations generated high IgG1 antibody titers that remained elevated even six months after the third immunization. In a previous study, it was described that the intra-nasal immunization with a recombinant protein containing the C-terminal region of the $P$. yoelii $\mathrm{MSP}_{19}$ antigen generated protective antibodies against an experimental challenge of mice against blood stage malaria (Hirunpetcharat et al. 1998). Together with our data, these results may open important perspectives for the development of an anti-malarial vaccine using this alternative administration route.

In our earlier work, we observed that the 13-amino acid long PADRE epitope AKFVAAWTLKAAA (Alexander et al. 1994) significantly improved the elicited antibody responses in mice immunized s.c. with vaccine formulations containing adjuvants other than complete/incomplete Freund's adjuvant (Rosa et al. 2004). In the present study, we found that the $\mathrm{His}_{6} \mathrm{MSP}_{19}$ antigen performed as well as the His ${ }_{6} \mathrm{MSP}_{1}{ }_{19}$-PADRE at inducing high specific serum antibody titers when injected by the i.n. route in the presence of CT or LT. These observations imply that CT and LT are endowed with strong adjuvant effects, similarly to the effect observed with the complete/incomplete Freund's adjuvant, and, therefore, do not require a strong activation of $\mathrm{T}$ helper cell response. Alternatively, it is possible that the T cell and/ or $\mathrm{B}$ cell activation thresholds differ according the ad- ministration route. In this regard, we recently observed that i.n. vaccination with a recombinant protein of Trypanosoma cruzi required B cells to prime specific $\mathrm{CD}^{+}$ and $\mathrm{CD}^{+} \mathrm{T}$ cells (MM Rodrigues, unpublished results). The fact that B cells are critical for the priming of cellmediated immune responses following i.n. administration of specific vaccine formulations may explain, at least in part, the distinct performance of the CD4 PADRE epitope.

The mechanisms implicated in the adjuvant activity of CT and LT remains elusive. The two toxins are members of the AB class bacterial toxins in which the enzymatically active ADP-ribosylating A subunit is responsible for the toxicity while the pentameric B subunit oligomer recognizes and binds to ganglioside receptors, such as GM-1, present on the surface of different cells types (Lavelle et al. 2004). The inherent toxicity of these molecules hampers their use in human trials, but the use of the nontoxic B subunit alone or detoxified whole molecule derivatives represent promising alternatives for the future pre-clinical and clinical testing of these vaccine formulations (Jakobsen et al. 2002, Holmgren et al. 2005, reviewed by Freytag \& Clements 2005, Holmgren \& Czerkinsky 2006).

Several groups have described CpG ODN 1826 as an effective mucosal adjuvant (reviewed by Holmgren \& Czerkinsky 2006). We observed that, for our recombinant proteins, CpG ODN 1826 showed less efficient adjuvant effects than $\mathrm{CT}$ or LT when administered via the i.n. route. Nevertheless, the synthetic oligonucleotides showed an excellent adjuvant activity when administered to mice via the s.c. route. Additionally, combination of CpG ODN 1826 with CT resulted in similar IgG responses with reduced bias toward a Th2 immune response pattern. Therefore, CpG ODN 1826 can be a useful adjuvant alternative for the differential activation of $\mathrm{T}$ helper response leading to a more balanced Th1-Th2 immune response.

In summary, our results demonstrated that strong and specific serum IgG responses can be achieved in mice immunized with important recombinant antigens derived from $P$. vivax by the i.n. administration in the presence of the adjuvants CT or LT. This observation may be useful for the rational design of new vaccine formulations against $P$. vivax malaria.

\section{REFERENCES}

Alexander J, Sidney J, Southwood S, Ruppert J, Oseroff C, Maewal A, Snoke K, Serra HM, Kubo RT, Sette A 1994. Development of high potency universal DR-restricted helper epitopes by modification of high affinity DR-blocking peptides. Immunity 1: 751-761.

Cunha MG, Rodrigues MM, Soares IS 2001. Comparison of the immunogenic properties of recombinant proteins representing the Plasmodium vivax vaccine candidate MSP1(19) expressed in distinct bacterial vectors. Vaccine 20: 385-396.

Freytag LC, Clements JD 2005. Mucosal adjuvants. Vaccine 23: 1804-1813.

Hirunpetcharat C, Stanisic D, Liu XQ, Vadolas J, Strugnell RA, Lee R, Miller LH, Kaslow DC, Good MF 1998. Intranasal immunization with yeast-expressed $19 \mathrm{kD}$ carboxyl-terminal 
fragment of Plasmodium yoelii merozoite surface protein-1 (yMSP119) induces protective immunity to blood stage malaria infection in mice. Parasite Immunol 20: 413-420.

Holmgren J, Czerkinsky C 2006. Mucosal immunity and vaccines. Nat Med (Suppl. 11): S45-53.

Holmgren J, Adamsson J, Anjuere F, Clemens J, Czerkinsky C, Eriksson K, Flach CF, George-Chandy A, Harandi AM, Lebens M, Lehner T, Lindblad M, Nygren E, Raghavan S, Sanchez J, Stanford M, Sun JB, Svennerholm AM, Tengvall S 2005. Mucosal adjuvants and anti-infection and anti-immunopathology vaccines based on cholera toxin, cholera toxin B subunit and CpG DNA. Immunol Lett 97:181-188.

Holmgren J, Czerkinsky C, Eriksson K, Mharandi A 2003. Mucosal immunisation and adjuvants: a brief overview of recent advances and challenges. Vaccine 21 (Suppl. 2): S89-95.

Jakobsen H, Bjarnarson S, Del Giudice G, Moreau M, Siegrist CA, Jonsdottir I 2002. Intranasal immunization with pneumococcal conjugate vaccines with LT-K63, a nontoxic mutant of heat-Labile enterotoxin, as adjuvant rapidly induces protective immunity against lethal pneumococcal infections in neonatal mice. Infect Immun 70: 1443-1452.

Lasaro MAS, Rodrigues JF, Mathias-Santos C, Guth BEC, RéguaMangia A, Ferreira AJ P, Takagi M, Cabrera-Crespo J, Sbrogio-Almeida ME, Ferreira LCS 2006. Production and release of heat-labile toxin (LT) by wild type human-derived enterotoxigenic Escherichia coli. FEMS Immunol Med Microbiol 48: 123-131.

Lavelle EC, Jarnicki A, McNeela E, Armstrong ME, Higgins SC, Leavy O, Mills KH 2004. Effects of cholera toxin on innate and adaptive immunity and its application as an immunomodulatory agent. J Leukoc Biol 75: 756-763.

Mendis K, Sina BJ, Marchesini P, Carter R 2001. The neglected burden of Plasmodium vivax malaria. Am J Trop Med Hyg 64: 97-106.

Rodrigues MH, Cunha MG, Machado RL, Ferreira OC Jr, Rodrigues MM, Soares IS 2003. Serological detection of Plasmodium vivax malaria using recombinant proteins corresponding to the $19-\mathrm{kDa} \mathrm{C}$-terminal region of the merozoite surface protein-1. Malar J 2: 39 .

Rosa DS, Tzelepis F, Cunha MG, Soares IS, Rodrigues MM 2004. The pan HLA DR-binding epitope improves adjuvant-assisted immunization with a recombinant protein containing a malaria vaccine candidate. Immunol Lett 92: 259-268.

Singh M, O'Hagan D 1999. Advances in vaccine adjuvants. Nat Biotechnol 17: 1075-1081.

Singh M, O'Hagan DT 2002. Recent advances in vaccine adjuvants. Pharm Res 19: 715-728. 
